\title{
Awareness of danger signs in pregnancy and post-partum period among antenatal mothers admitted to General Hospital Matara
}

\author{
Edirisinghe EARC ${ }^{1}$, Rupasinghe $\mathrm{JAS}^{2}$, Wijesinghe $\mathrm{CJ}^{3}$
}

\begin{abstract}
Introduction: Pregnancy related deaths and disabilities are a major public health problem worldwide. Poor knowledge of obstetric danger signs leads to delay in care seeking causing maternal deaths and complications. However, few studies are conducted in Sri Lanka to evaluate this aspect.
\end{abstract}

Aim: To describe the awareness of danger signs in pregnancy and post-partum period and related factors among antenatal mothers admitted to General Hospital, Matara.

Materials and Methods: A sample of 395 antenatal mothers in late pregnancy admitted to General Hospital, Matara were studied using an interviewer-administered questionnaire. Data were analyzed using SPSS software. Chi-square test was used to assess the association between variables.

Results: The level of awareness of obstetric danger signs was good in $73.7 \%$ of the mothers. Bleeding $(75.9 \%)$, dribbling (51.6\%) and pain (58.2\%) were the common dangers signs identified. Approximately $15 \%$ did not know of any danger sign. A better awareness of danger signs was significantly associated with primiparity, higher educational level of mother/spouse and mother being employed (all $p<0.05$ ).

Conclusions and recommendations: Awareness of obstetric danger signs was satisfactory among the majority of antenatal mothers, despite lack of knowledge on some important danger signs. Educational programmes should be designed to raise awareness on danger signs, specifically targeting the high risk groups identified during this study.

Key words: pregnancy, post-partum, obstetric danger signs

1. Medical officer Postgraduate Institute of Medicine, University of Colombo

2. Medical officer National Hospital, Sri Lanka

3. Senior lecturer Department of Community Medicine, Faculty of Medicine, University of Ruhuna

https://orcid.org/0000-0002-9005-7080

\section{Introduction}

Despite the miraculous development of technologies over the past few decades and advances in health care delivery that parallels it, high levels of maternal mortality remains a major public health challenge throughout the world. Around 830 women die from pregnancy or childbirth related complications across the world everyday. ${ }^{1}$ Almost all of these maternal deaths occur in developing countries. ${ }^{1}$ It was estimated that in 2015, approximately 303000 women died during and following pregnancy and childbirth. ${ }^{1}$ More than half of these deaths occurred in sub-Saharan Africa and almost one third occurred in South Asia, the majority of these deaths being preventable. Another millions of women who just escaped from the death are known to suffer from severe ill health or lifelong disabilities. ${ }^{2}$

In Sri Lanka, too maternal mortality is a significant public health issue. The top most causes of maternal deaths in the year $\mathbf{2 0 1 4}$ were respiratory disease, exaggeration of heart disease, complications of abortion and obstetric haemorrhage. ${ }^{3}$ The national reviews reveal that $62 \%$ of maternal deaths were preventable. A further analysis indicates that $57.1 \%$ of the Sri Lankan mothers did not seek health care in time for their illnesses. ${ }^{3}$

The preventable factors of maternal mortality are best explained in 3-delay (3D) model proposed by Thaddeus and Maine in 1994. They include (i) delay in deciding to seek health care, (ii) delay in reaching a health facility and (iii) delay in receiving proper care at the facility. ${ }^{4}$ In some studies, this concept has been modified as a '4-delay model' by adding the recognition of danger signs as the first delay. ${ }^{5}$

Danger signs are only the alarms and not the actual complications. Those are the symptoms which can be easily identified by non-clinical personnel. ${ }^{6}$ Therefore, having knowledge of these signs is the definite first step in the process of receiving appropriate essential obstetric care in time. ${ }^{6}$ Thus, inadequate awareness of danger signs in pregnancy plays a major role in causing maternal morbidity and mortality as it may delay care seeking by the pregnant mother. It has been found that poor knowledge of danger signs is accountable for around one third of total delay in receiving obstetric care. ${ }^{5}$

There are several key danger signs in pregnancy which are common and easily recognizable, yet related to potentially severe conditions. ${ }^{6}$ These key danger signs 
include swollen hands/face and blurred vision during pregnancy, prolonged labour (>12 hours), convulsions and retained placenta during childbirth, foul-smelling vaginal discharge and high fever during the postpartum period with severe vaginal bleeding in all three stages. ${ }^{6}$

Though the important obstetric danger signs must be a common knowledge among women in reproductive age, the majority of pregnant and post-partum women worldwide have unsatisfactory level of knowledge on the danger signs. ${ }^{7,8,9}$ There is a paucity of research evidence on level of knowledge about obstetric danger signs among women in the Sri Lankan context. Therefore, this study was conducted to assess the level of knowledge regarding obstetric danger signs and identify related factors among antenatal mothers attending a secondary care institution in Matara. The findings would reveal possible deficiencies in knowledge and vulnerable groups, facilitating the design and implementation of educational interventions to improve their awareness, thereby reducing the first delay leading to maternal mortality and morbidity.

\section{Methodology}

This study was an institution-based descriptive, cross sectional study conducted as a part of a larger survey on pregnancy planning and birth preparedness, carried out in General Hospital (GH), Matara. GH, Matara is a secondary care institution which drains clients from all over the district catering to a population of 814,048 with the distribution of $11.9 \%$ of the population in urban, $85.4 \%$ in rural and $2.8 \%$ in estate sectors. ${ }^{10}$

A convenient sample of 395 ante-natal mothers with a period of amenorrhoea (POA) of 36 weeks or above, admitted to the two obstetric units in GH, Matara were recruited for the study. The mothers with a POA less than 36 weeks and those with difficulties in understanding the questionnaire were excluded from the study. Data on awareness of danger signs and other study variables were collected using a pre-tested, interviewer-administered questionnaire which assesses the spontaneous knowledge of danger signs of obstetric complications. (Spontaneous knowledge refers to the respondent's naming a sign without being asked about that sign by name). ${ }^{6}$ In addition, details of the basic demographic characteristics of the sample were also obtained. All data were collected by the principal investigator and a trained pre-intern medical officer, after explaining the purpose and objectives of the study to the participants.

The level of knowledge on obstetric danger signs was assessed based on the total number of danger signs known by the pregnant mother. If the number of danger signs known was three or more, it was considered as a good level of knowledge, in keeping with the criteria used by other researchers in various settings. ${ }^{8,12}$ Data was analyzed using SPSS statistical software package (Version 17.0). Chi square test was used to assess the association between study variables. Significance level was set at 0.05 .

Ethical approval for the study was obtained from Ethical Review Committee of the Faculty of Medicine, University of Ruhuna and administrative approval was obtained from the Director, GH, Matara. Written informed consent was obtained from each pregnant woman prior to data collection.

\section{Results}

Basic characteristics of the study participants

The majority of the pregnant mothers in the sample were Sinhalese and Buddhists (over 94\%), married ( $n=384$, $97.2 \%)$, from rural areas ( $n=327,82.8 \%)$, educated up to G.C.E. Ordinary Level $(n=191,48.4 \%)$ and aged between $18-34$ years ( $n=330,83.5 \%$ ). Only $20.3 \%$ of the mothers $(n=80)$ were employed. Approximately $43 \% \quad(n=169)$ were pregnant for the first time.

Awareness of obstetric danger signs among the pregnant mothers in the sample

Most mothers were able to identify a few common danger signs. The commonest sign identified was bleeding (75.9\%). Pain and dribbling were identified by more than half of the mothers. However, awareness of common and important danger signs such as ankle oedema, headache and smelly vaginal discharge were very low (Table 1 ).

A good level of awareness on obstetric danger signs (defined as knowing at least 3 danger signs) was observed among 291 mothers (73.7\%), while over a quarter of the mothers in the sample had a poor knowledge. The main source of awareness was Public Health Midwife (79.0\%). The next important source was print media (8.4\%). The direct contribution of other health staff in building awareness about the danger signs was insignificant.

The association between the level of awareness and basic characteristics of the mothers

A good level of awareness regarding obstetric danger signs was significantly associated with primiparity, better educational status of pregnant mother and husband and being employed by the pregnant mother. Respondent's age, ethnicity, area of residence, marital status and income were not significantly associated with level of awareness of danger signs (Table 3). 
Table 1. The distribution of awareness of obstetric danger signs among antenatal mothers in the sample

\begin{tabular}{|c|c|c|c|c|c|c|}
\hline \multirow{3}{*}{ Sign/Symptom } & \multicolumn{4}{|c|}{ Identified as a danger sign } & \multirow[b]{3}{*}{ No. } & \multirow{3}{*}{$\begin{array}{l}\text { Total } \\
\%\end{array}$} \\
\hline & \multicolumn{2}{|c|}{ Yes } & \multicolumn{2}{|c|}{ No } & & \\
\hline & No. & $\%$ & No. & $\%$ & & \\
\hline Bleeding & 300 & 75.9 & 95 & 24.1 & 395 & 100.0 \\
\hline Pain & 204 & 51.6 & 191 & 48.4 & 395 & 100.0 \\
\hline Dribbling & 230 & 58.2 & 165 & 41.8 & 395 & 100.0 \\
\hline Faintishness & 4 & 1.0 & 391 & 99.0 & 395 & 100.0 \\
\hline Reduced fetal movements & 155 & 39.2 & 240 & 60.8 & 395 & 100.0 \\
\hline High blood pressure & 24 & 6.1 & 371 & 93.9 & 395 & 100.0 \\
\hline Headache & 6 & 1.5 & 389 & 98.5 & 395 & 100.0 \\
\hline Ankle oedema & 1 & 0.3 & 394 & 99.7 & 395 & 100.0 \\
\hline Vertigo & 1 & 0.3 & 394 & 99.7 & 395 & 100.0 \\
\hline Smelly vaginal discharge & 6 & 1.5 & 389 & 98.5 & 395 & 100.0 \\
\hline Fits & 1 & 0.3 & 394 & 99.7 & 395 & 100.0 \\
\hline Fever & 42 & 10.6 & 353 & 89.4 & 395 & 100.0 \\
\hline Vomiting & 5 & 1.3 & 390 & 98.7 & 395 & 100.0 \\
\hline Infection & 46 & 11.6 & 349 & 88.4 & 395 & 100.0 \\
\hline
\end{tabular}

Though the majority (84.8\%) of the pregnant mothers was aware of at least one danger sign, there was a considerable proportion (15.2\%) who did not know any danger sign (Table 2). The mothers in this sample knew only five danger signs or fewer. Majority of the mothers were aware of only three danger signs (57.5\%).

Table 2. The level of awareness of obstetric danger signs among the antenatal mothers in the sample ( $\mathrm{N}=395$ )

$\begin{array}{llr}\text { Awareness of danger signs } & \text { No. } & \% \\ \text { Number of danger signs known } & & 15.2 \\ 0 & 60 & 0.8 \\ 2 & 3 & 10.4 \\ 3 & 41 & 57.5 \\ 4 & 227 & 15.2 \\ 5 & 60 & 1.0\end{array}$

Mean $\pm S D=2.6 \pm 1.2$ signs, Minimum/Maximum $=0 / 5$ signs

Level of awareness of obstetric danger

signs

Good 
Table 3. Association between the awareness of obstetric danger signs and the characteristics of pregnant mothers $(\mathrm{N}=395)$

\begin{tabular}{|c|c|c|c|c|c|c|c|}
\hline \multirow{3}{*}{ Characteristics } & \multirow{2}{*}{\multicolumn{2}{|c|}{$\begin{array}{l}\text { Awareness } \\
\text { Poor }(<3)\end{array}$}} & \multirow{2}{*}{\multicolumn{2}{|c|}{$\begin{array}{c}\text { of obstetric } \\
\text { Good }(\geq 3)\end{array}$}} & \multirow{2}{*}{\multicolumn{2}{|c|}{$\frac{\text { danger signs }}{\text { Total }}$}} & \multirow{3}{*}{$P$ value } \\
\hline & & & & & & & \\
\hline & No. & $\%$ & No. & $\%$ & No. & $\%$ & \\
\hline \multicolumn{8}{|c|}{ Age in completed years } \\
\hline 30 years or below & 67 & 27.6 & 181 & 72.4 & 250 & 100.0 & \multirow{2}{*}{$p=0.451$} \\
\hline Above 30 years & 35 & 24.1 & 110 & 75.9 & 145 & 100.0 & \\
\hline \multicolumn{8}{|l|}{ Sector } \\
\hline Urban & 15 & 25.0 & 45 & 75.0 & 60 & 100.0 & \multirow{2}{*}{$p=0.800$} \\
\hline Rural \& Estate & 89 & 26.6 & 246 & 73.4 & 335 & 100.0 & \\
\hline \multicolumn{8}{|l|}{ Ethnicity } \\
\hline Sinhalese & 97 & 25.9 & 277 & 74.1 & 374 & 100.0 & \multirow{2}{*}{$p=0.454$} \\
\hline Other & 7 & 33.3 & 14 & 66.7 & 21 & 100.0 & \\
\hline \multicolumn{8}{|l|}{ Marital status } \\
\hline Unmarried & 2 & 18.2 & 9 & 81.8 & 11 & 100.0 & \multirow{2}{*}{$p=0.534$} \\
\hline Married & 102 & 26.6 & 282 & 73.4 & 384 & 100.0 & \\
\hline \multicolumn{8}{|l|}{ Parity } \\
\hline Primiparous & 34 & 20.1 & 135 & 79.9 & 169 & 100.0 & \multirow{2}{*}{$p=0.015$} \\
\hline Multiparous & 70 & 31.0 & 156 & 69.0 & 226 & 100.0 & \\
\hline \multicolumn{8}{|c|}{ Maternal educational status } \\
\hline Below G.C.E. O/ L & 64 & 31.2 & 141 & 68.8 & 205 & 100.0 & \multirow{2}{*}{$p=0.022$} \\
\hline G.C.E. O/ L or above & 40 & 21.1 & 150 & 78.9 & 190 & 100.0 & \\
\hline \multicolumn{8}{|c|}{ Educational status of the husband } \\
\hline Below G.C.E. O/ L & 67 & 30.5 & 153 & 69.5 & 220 & 100.0 & \multirow{2}{*}{$p=0.037$} \\
\hline G.C.E. O/ L or above & 37 & 21.1 & 138 & 78.9 & 175 & 100.0 & \\
\hline \multicolumn{8}{|c|}{ Maternal employment status } \\
\hline Not employed & 92 & 29.2 & 223 & 70.8 & 315 & 100.0 & \multirow{2}{*}{$p=0.010$} \\
\hline Employed & 12 & 15.0 & 68 & 85.0 & 80 & 100.0 & \\
\hline \multicolumn{8}{|c|}{ Average monthly family income } \\
\hline Rs. 25000 or below & 60 & 24.8 & 182 & 75.2 & 242 & 100.0 & \multirow{2}{*}{$p=0.383$} \\
\hline Above Rs. 25000 & 44 & 28.8 & 109 & 71.2 & 153 & 100.0 & \\
\hline
\end{tabular}

\section{Discussion}

Most pregnancy related complications can be effectively prevented or managed without recourse to sophisticated and expensive technologies or drugs. Experience has shown that maternal and neonatal mortality can be reduced effectively, when communities are well aware of obstetric danger signs. ${ }^{2}$
The level of the awareness on danger signs was good among $73.7 \%$ of the mothers while over $1 / 4^{\text {th }}$ of the mothers in the sample had a poor knowledge. This is comparable with the results of a study conducted in Lagos State, Nigeria, where nearly $70 \%$ of the pregnant mothers were found to have a good knowledge on danger signs, ${ }^{13}$ though a study done in Northwest Ethiopia revealed that only $55 \%$ of the post-natal mothers had a 
good knowledge. ${ }^{14}$ Many similar studies have revealed that the level of knowledge on danger signs in pregnancy and postpartum is unsatisfactory among the majority of women in developing countries. ${ }^{7,8,9}$

Majority of the mothers in this sample were knowledgeable about few common danger signs. Bleeding was known by more than $3 / 4^{\text {th }}$ of the sample and pain and dribbling were identified by more than half of the mothers. However, all of these could be seen in normal labour also if they occurred within usual amount and time limits. Interestingly, some of the critical obstetric danger signs were identified by a very small proportion only. Corresponding to the findings of this study, bleeding was the commonest danger sign identified by women in all most all studies in developing countries and knowledge about other important danger signs was significantly low. ${ }^{9,11,12}$ It is important to note that, a considerable proportion (15.2\%) of mothers in this study did not know any danger sign. Similar findings from studies done in other settings such as Tigray region of Ethiopia (>30\%) and Southeast Nigeria (17\%) indicate that such lack of awareness is a common occurrence. ${ }^{11,15}$

Though awareness of danger signs was good among the majority on the basis of the number of known symptoms/ signs, the quality of their knowledge is questionable as a considerable proportion failed to recognize certain key danger signs which are used in developing indicators for maternal and newborn health. ${ }^{6}$ Only $10.6 \%$ of the mothers identified fever as a danger sign and an alarmingly low proportion knew of danger signs such as smelly vaginal discharge (1.5\%) ankle oedema and convulsions $(0.3 \%)$. As these signs/symptoms point towards potentially life threatening conditions, failure to recognize them as danger signs may lead to disastrous consequences.

Main source of awareness of obstetric danger signs was Public Health Midwife (79.0\%). The direct contribution of other health staff in building awareness regarding obstetric danger signs was relatively insignificant (6.0\%). Our findings are comparable to that of an Ethiopian study where most frequently reported sources of information were health care providers $(76.3 \%)$, though the contribution of the mass media was found to be much higher (20.5\%) than the findings of this study $(10.7 \%) .{ }^{14}$

Among the mothers in this study, the association between awareness of danger signs and basic demographic characteristics such as age, ethnicity, residential area, marital status and income were not statistically significant. Existing literature provides contrasting evidence regarding urban-rural disparity of knowledge. Results comparable to the present study were observed in some settings, ${ }^{14}$ whereas in other settings a significantly higher knowledge of danger signs was observed among urban population..$^{8,9}$ This difference could be partially explained by the marked discrepancy of the accessibility of health care and availability of other facilities such as electronic media between different sectors in those countries. ${ }^{15}$

Contrary to the findings of studies conducted in Northwest and Somali regions of Ethiopia, a higher proportion of primi mothers in this study had a good knowledge of danger signs compared to multiparous mothers. The first-time mothers are likely to be highly concerned about the course of pregnancy as it is a new experience for them, thus making them more aware about the possible dangers. They are also more likely to attend antenatal awareness programmes, which would have contributed to a greater knowledge of danger signs - an assumption which is supported by the fact that Public Health Midwife was the main source of awareness in this sample. Moreover, Public Health Midwives' services are freely available and accessible to all clients irrespective of income level, which may explain why income was not associated with level of awareness, though this finding is not in line with other research evidence. ${ }^{7,14}$

Also, in consistence with previous studies conducted in Ethiopia, Malaysia and Nigeria, a good level of awareness on danger signs was significantly associated with higher educational levels of both pregnant mother and her husband and employment status of the pregnant mother. ${ }^{7,} 9,11,13,14$ As these variables are somewhat interconnected, the observed associations could be due to potential confounding effect mediated through high maternal health literacy.

Researchers in other settings have assessed the association between the knowledge of obstetric danger signs and antenatal care coverage or institutional deliveries (in contrast to home deliveries). ${ }^{8,9,14,15}$ However, they were not considered as variables in this study as both parameters show a nearly universal coverage in Sri Lanka. ${ }^{3}$

Since this was an institution-based study, conducted among a convenient sample of pregnant mothers admitted in a government health facility, generalizability of the findings could be a potential limitation. However, since over $90 \%$ of all deliveries take place in such hospitals, we can safely assume that the sample studied is fairly representative of the general population of antenatal mothers. Assessing the level of knowledge based on the total number of danger signs known by the pregnant mother is another limitation as it did not take into account the nature of danger signs known to them and their awareness of important key signs. 


\section{Conclusions \& Recommendations}

Although knowledge on danger signs was satisfactory among the majority, lack of awareness on some important danger signs was observed. Therefore, awareness should be increased on those important danger signs. Future educational programs should be targeted at vulnerable groups identified during this study, to raise awareness among those mothers. Use of media as a source of knowledge on danger signs should be encouraged as maternal literacy rate is high in the local setting.

\section{Acknowledgement}

Authors wish to acknowledge the director, GH, Matara and all the consultants in charge of the obstetric units for granting permission and all the staff in obstetric wards for their kind co-operation in conducting this study. All the mothers who participated in the study are gratefully acknowledged.

\section{References}

1. World Health Organization. Maternal mortality fact sheet-Updated November 2016. http://www.who. int/mediacentre/factsheets/fs348/en/

2. World Health Organization, Maternal health and safe motherhood programme. Mother-Baby Package: Implementing Safe Motherhood in Countries, Geneva, World Health Organization. 1996: 1-14.

3. Family Health Bureau. Annual Report of Family Health Bureau 2014. In: Kasturiaratchi K, eds. Maternal and Newborn Care. Colombo, Sri Lanka; Ministry of Health. 2015: 28-50.

4. Thaddeus S, Maine D. Too far to walk: maternal mortality in context. Soc Sci Med 1994; 38: 10911110

5. Ghebrehiwet $\mathrm{M}$, Morrow RH. Delay in seeking and receiving emergency obstetric care in Eritrea. Journal of Eritrean Medical association 2007; 2(1): 8-13. http://dx.doi.org/10.4314/jema.v2i1.52695

6. Johns Hopkins Bloomberg School of public health. Monitoring Birth preparedness and complication readiness-tools and indicators for maternal and newborn health. In: Barco RCD, eds. Birth preparedness and complication readiness index indicator definitions. Baltimore: JHPIEGO, 2004: 2425 in part 1. http://www.jhpiego.org/files/BPCR toolkit.pdf-birth
7. Teng SP, Zuo TC, Jummaat FB, Keng SL. Knowledge of pregnancy danger signs and associated factors among Malaysian mothers. British Journal of Midwifery 2015; 23(11): 800-806. DOI: 10.12968/ bjom.2015.23.11.800

8. Bogale D, Markos D. Knowledge of obstetric danger signs among child bearing age women in Goba district, Ethiopia: a cross-sectional study. BMC Pregnancy and Childbirth 2015; 15(77). DOI 10.1186/ s12884-015-0508-1

9. Maseresha N, Woldemichael K, Dube L. Knowledge of obstetric danger signs and associated factors among pregnant women in Erer district, Somali region, Ethiopia. BMC Women's Health 2016; 16(30). DOI 10.1186/s12905-016-0309-3

10. Department of Census \& Statistics. Census of Population and Housing 2012, Final report. Ministry of Policy Planning and Economic Affairs, Sri Lanka. 2015: 52.

11. Ossai EN, Uzochukwu BS. Knowledge of Danger Signs of Pregnancy among Clients of Maternal Health Service in Urban and Rural Primary Health Centres of Southeast Nigeria. J Community Med Health Educ 2015; 5(2): 337. doi:10.4172/2161-0711.1000337

12. Kabakyenga JK, Ostergre PO, Turyakira E, Pettersson KO. Knowledge of obstetric danger signs and birth preparedness practices among women in rural Uganda. Reproductive Health 2011; 8(33). doi:10.1186/1742-4755-8-33

13. Oni B, Odukoya OO, Okunowo AA, Ojo OY, Abatan YO. A comparative assessment of the awareness of danger signs and practice of birth preparedness and complication readiness among pregnant women attending rural and urban general hospitals in Lagos State. Sahel Med J 2016; 19:206-214. doi:10.4103/1118-8561.196364

14. Amenu G, Mulaw Z, Seyoum T, Bayu H. Knowledge about Danger Signs of Obstetric Complications and Associated Factors among Postnatal Mothers of Mechekel District Health Centers, East Gojjam Zone, Northwest Ethiopia, 2014. Scientifica 2016; 2016:3495416. doi:10.1155/2016/3495416

15. Hailu D, Berhe H. Knowledge about Obstetric Danger Signs and Associated Factors among Mothers in Tsegedie District, Tigray Region, Ethiopia 2013: Community Based Cross-Sectional Study. PLoS ONE 2014; 9(2): e83459. doi:10.1371/journal. pone.0083459 